\title{
Neurogenic Stress Effects on the Immune System Functional State
}

\author{
Fishman $\mathrm{B}^{1 *}$, Tapbergenov T¹, Azovceva 01, Kulikov V², Khaybullin \\ $\mathrm{T}^{3}$, Tkachenko $\mathrm{T}^{1}$, Yukhno $\mathrm{M}^{1}$, Lole $0^{1}$, Shevnina $\mathrm{E}^{2}$, Kazakova $\mathbf{0}^{2}$, \\ Nikolaeva $\mathrm{K}^{2}$ and Amirbekov $\mathrm{A}^{1}$ \\ 1Yaroslav-The-Wise Novgorod State University, Russia \\ ${ }^{2}$ Ulyanovsk State University, Russia \\ ${ }^{3}$ Semey State Medical University, Kazakhstan
}

*Corresponding author: Boris Fishman, Institute of Medical Education, Yaroslav-The-Wise Novgorod State University Ministry of Education and Science of the Russian Federation, Russia, Email: Fishman@mxc.ru

\section{Research Article \\ Volume 2 Issue 10}

Received Date: September 14, 2018

Published Date: September 20, 2018

\begin{abstract}
According to most researchers, stress is one of the main causes of the ever increasing number of cardiovascular, gastrointestinal, neurologic and other diseases. In addition to acute damage to organs and systems, stress causes exacerbation of chronic diseases, and also suppresses the immune system. Controlled and uncontrolled stress causes reversible and irreversible changes in the body. If reversible changes in controlled stress lead to the development of adaptation to external influences, irreversible changes can lead to the death of the organism. Given the close attention of researchers to stress, research on the mechanisms for developing the body's adaptation to stressful influences is a major problem in modern biology and medicine.

At the same time, the stress response is a necessary link in the adaptation of the organism. However, with an overly intense and prolonged exposure to stress factors, the response significantly reduces the overall resistance of the organism, turning stress reaction from an adaptation link to a pathogenesis link of various diseases.

Adaptation of the human and animal organism to constantly changing environmental conditions is one of the main problems of medical and biological science.
\end{abstract}

Keywords: Neurogenic Stress; Immune Response; Adaptation; Disadaptation

\section{Introduction}

Numerous data published in recent years indicate the existence of complex mechanisms of interaction, integration of the immune, endocrine and nervous systems [1-5]. Thus, the formation of an immune response is accompanied by the use of the afferent part of the nervous system and the change in the molecular biological, biochemical and electrophysiological parameters of a number of brain structures (hypothalamus, pituitary, hippocampus and others). For example, administration of E. coli lipopolysaccharide to experimental animals is accompanied by a significant increase in the number of IL-1 $\beta$-positive cells, as well as IL-1 $\beta$, IL-1RA, IL-6 and TNF $\alpha$ mRNA expression in the hypothalamus, pituitary gland, hippocampus, striatum, 


\section{Virology \& Immunology Journal}

circumventricular structures. In this regard, the activation of immunocompetent cells obligatorily leads to a change in cortical functions. In addition, there are data on the direct modulation of cortical functions during immunogenesis. Consequently, the formation of an immune response to specific antigens is accompanied by a modulation of functional activity, both subcortical structures and the cortex of the cerebral hemispheres. As a result, the efferent part (the autonomic nervous system and the hypothalamic-pituitary-adrenal axis) are subsequently "included" in the regulatory process [5-7].

It seems that the change in the functional parameters of the central nervous system during the formation of an immune response may be a consequence of several mechanisms' initiation. First, there is evidence that the formation of an immune response in the lymphoid organs is accompanied by an adequate change in the functional activity of the sensory nerve endings in the stroma and parenchyma. In this case, the change in the membrane potential of activated immunocompetent cells, as well as the cytokines produced by them, capable of affecting sensory nerve structures through specific receptors, can act as trigger factors leading to these changes. Secondly, the penetration of cytokines and even immunocompetent cells from systemic circulation into brain parenchyma through intact blood-brain barrier has been reported [8]. Moreover, the initiation of these mechanisms is undoubtedly capable of leading foremostly to modulations of the functional parameters of the central nervous system, and then to the activation of the autonomic nervous system and the hypothalamicpituitary-adrenal axis in the process of immunoregulation.

Estimating the stress-induced suppression of immune reactions, it is shown that the task of the immune system is to maintain a hereditarily determined individuality of the organism. This task covers two areas: first, the elimination of exogenous "non-own" structures and, secondly, the destruction of endogenous "changed" structures, the formation of which takes place in large numbers with the constant restructuring of the cellular elements of the organism [5,9]. According to a certain opinion, elimination of exogenous "not their" structures is the primary task of humoral immune reactions of B cells. On the other hand, the destruction of endogenous "altered" structures is the primary objective of cellular immune responses of cytotoxic T cells and natural killers. Immunological health as a whole depends on a harmonious relationship between the humoral and cellular immune responses. Studies aimed at identifying neural ways to regulate the immune response have been initiated because of the availability of data suggesting that psychological stress and depression can alter the function of the human immune system, and immune responses in animals can be due to the classical Pavlovian paradigm, and that neural damage can inhibit various aspects of the immune response [10]. These changes can affect the immune system and are important for the course of cancer, acquired immunodeficiency syndrome (AIDS), and for initiating or impairing autoimmune diseases, including endocrine-related diseases. The degree of influence of these factors, (if they actually exist) through known neuroendocrine pathways, is unknown. Alternative regulatory pathways from the central nervous system to the immune system include the catecholamines and neuropeptides of the autonomic nervous system that innervates the lymph nodes, spleen and thymus, adrenomedullary catecholamines and hormones that affect the secretion of thymosin and other regulatory thymic hormones. Despite the evidence that the nervous system can affect immune function through neural and neuroendocrine mechanisms, the role of these factors in human inflammatory diseases has not yet been determined.

The nervous system can affect the immune function through a variety of mechanisms: through the hypothalamic-pituitary function, through the innervation of the autonomic nervous system of the spleen, liver, intestine and lymphoid organs, through the circulation of catecholamines, through sensory peptides such as somatostatin, substance $P$ and with changes in diet and activity. A less known mechanism is the direct secretion into the blood of the immune-controlling factors by the brain.

The most important hormone that affects immune responses is cortisol, which inhibits most aspects of the immune response, including proliferation of lymphocytes, the production of immunoglobulins, cytokines and inflammatory mediators and cellular toxicity, and the production of inflammatory leukotrienes. This inhibitory reaction is based on the anti-inflammatory effect of glucocorticoids and occurs within the range of values induced by stress or inflammation. The pituitary-adrenal response to stress can influence the intensity of the immune response and the produced inflammatory components, including changes in the tone and patency of the vessels. The loss of this function makes animals with adrenal insufficiency vulnerable to inflammation. The fact that inflammatory mediators of the IL-1 type can activate the hypothalamic-pituitary-adrenal axis suggests a 


\section{Virology \& Immunology Journal}

negative feedback loop to regulate the intensity of the inflammation. Since the pituitary-adrenal function is almost completely controlled by the brain, this system is an excellent example of neuroimmunomodulation.

The influence of other hormones of the anterior pituitary gland on the immune function is more subtle. Gonadotropin-deficient mice show thymic atrophy, lymphatic tissue involution and T-cell damage-functional dysfunctions that are reversible by gonadotropin administration. In addition, a decrease in gonadotropin secretion during aging can cause chronic impairment of the immune function. Atrophy of the thymus in old rats is completely reversible by gonadotropin administration. Prolactin can also stimulate the immune function. $\mathrm{T}$ and B-lymphocytes and some lymphoma cells contain membrane prolactin receptors; impaired immunocompetence in hypophysectomized mice is shown to be corrected by prolactin administration; antibodies to prolactin inhibit the proliferation of lymphocytes of several cell lines; immunosuppressive cyclosporine blocks the prolactin effect of stimulating lymphocytes. Such an effect of prolactin on lymphocytes might be pituitary-mediated, but also might occur due to an autocrine or paracrine regulation, since lymphocytes themselves produce prolactin. The effect of hyperprolactinemia and prolactin inhibition of human immune function has not yet been explained.

Adrenocorticotropic hormone, vasopressin and $\alpha$ melanocyte stimulating hormone (MSH) are pyrogeninduced fever inhibitors. MSH at the periphery counteracts some effects of IL-1 on the function of fibroblasts and monocytes.

Other neuropeptides that affect the immune response include substance $\mathrm{P}$, somatostatin, corticoliberin, and vasointestinal peptide (VIP). The concentrations required for the biological effect appear to be too high to be physiologically effective through circulatory transport, but these peptides can be produced by peripheral sensory nerve endings and immunocompetent inflammatory cells creating considerably high local concentrations.

The secretion of pituitary hormones in lymphocytes is regulated by the same factors that their secretion is regulated in the pituitary gland. For example, secretion of adrenocorticotropic hormone by lymphocytes is suppressed by glucocorticoids and stimulated by a corticotropin-releasing factor; immunoreactivity of lymphocytes is stimulated by thyrotropin-releasing hormone (TRH) and is suppressed by thyroid hormone. The endocrine value of hormone secretion by lymphocytes is not determined. For example, lymphocytes from hypophysectomized mice infected with the Newcastle virus can synthesize a sufficient amount of adrenocorticotropic hormone to stimulate the adrenal cortex. One of the studies was criticized on methodological grounds, however, the case of Cushing's syndrome was apparently caused by excessive secretion of adrenocorticotropic hormone by a large area of inflammation. In addition, there are conflicting data as to whether adrenocorticotropic hormone receptors are present on lymphocytes or not.

\section{Methods}

The experimental part of the study was carried out on sexually mature rats of the Wistar and August lines (study of the purine nucleotide metabolism) weighing 170-180 g. In the first series of experiments in stress resistant Wistar rats, neurogenic stress was caused by applying extreme stimulation to the reflexogenic zone of the aortic arch with an impulse current for three hours. In the second series of experiments in August rats, predisposed to stress, neurogenic stress was caused by immobilizing the animals upside down with a load of $35 \mathrm{~g}$ per $100 \mathrm{~g}$ of body weight for 60 minutes.

Three-hour electrostimulation of the aortic arch is known to produce neurogenic stress response and cause a small-scale dystrophic myocardial lesion with a depletion of tissue norepinephrine. Using a slight ether anesthesia, a thin polyethylene insulated nichrome electrode with a diameter of $120 \mu \mathrm{m}$ was inserted in into the aortic arch through the right common carotid artery. The distal end of the electrode, 0.3-0.5 mm long, was left in isolation in the lumen of the arch, the proximal end was taken through the skin into the region of the right ear and fixed on a gauze pad. After 1 day, the animals were immobilized and the electrode located in the aorta was connected to a square-wave generator output. A platinum electrode was inserted under the skin of the left forelimb and electrostimulation of the aortic arch was performed for 3 hours at a pulse frequency of $50 \mathrm{~Hz}$, a pulse duration of 10 $\mathrm{ms}$, and a voltage of 5-7 V.

After carrying out electrostimulation, changes in the PQRS waves' voltage and the shortening of the R-R interval were noted on the ECG. However, the most noticeable was the decrease in the voltage of the $\mathrm{T}$ wave and the shift of the ST interval below the isoelectric line. These changes indicate dystrophic and hypoxic damage to the myocardium, caused by extreme stimulation of the reflex zone of the aortic arch. Tissue samples were taken 


\section{Virology \& Immunology Journal}

after ECG recording. Sections of the myocardium samples were studied using optical microscope, cell infiltration, swelling and vacuolation of muscle fibers with loss of striation were noted.

The immune system was examined by flow cytometry, assessing total count of lymphocytes, T-lymphocytes (CD3 $+)$ and B-lymphocytes (CD72 +) in peripheral blood. Subpopulations of $\mathrm{T}$ cells with suppressor and helper activity were identified, including theophylline-sensitive rosette-forming cells (TRFC-sens) and theophyllineresistant rosette-forming cells (TRFC-res). Number of circulating immune complexes and phagocytic activity were also assessed [11].

\section{Results}

Functional state of the immune system in neurogenic stress was assessed in experiment on August rats. Intact animals were included in the control group. The study group included animals in which neurogenic stress was caused by immobilization. The results of the study are presented in Table 1.

\begin{tabular}{|c|c|c|c|c|c|}
\hline \multirow{2}{*}{ Indicator } & \multirow{2}{*}{ Control group } & \multicolumn{4}{|c|}{ Time after stress was caused } \\
\cline { 3 - 6 } & & $\mathbf{2 4}$ hours & $\mathbf{4 8}$ hours & $\mathbf{7 2}$ hours & $\mathbf{1 2 0}$ hours \\
\hline Lymphocytes & $4586 \pm 321$ & $4910 \pm 128$ & $4730 \pm 144$ & $4927 \pm 136$ & $4779 \pm 149$ \\
\hline LMIT (PHA) & $0.82 \pm 0.06$ & $1.44 \pm 0.02^{*}$ & $0.92 \pm 0.02$ & $1.00 \pm 0.10$ & $0.81 \pm 0.07$ \\
\hline Suppressor cell index & $61.1 \pm 1.6$ & $52.2 \pm 1.2$ & $53.6 \pm 1.4$ & $66.5 \pm 1.5$ & $62.2 \pm 1.4$ \\
\hline CIC & $1.36 \pm 0.03$ & $0.70 \pm 0.01^{*}$ & $0.36 \pm 0.06^{* *}$ & $0.67 \pm 0.08^{* *}$ & $1.07 \pm 0.03$ \\
\hline AFC & $52.0 \pm 4.9$ & $26.0 \pm 2.5^{*}$ & $24.0 \pm 3.7^{*}$ & $17.5 \pm 1.9^{* *}$ & $20.0 \pm 1.9^{* *}$ \\
\hline Phagocytic activity & $36.2 \pm 2.4$ & $12.4 \pm 1.6^{*}$ & $26.0 \pm 1.6^{* *}$ & $16.7 \pm 2.4^{* *}$ & $32.4 \pm 1.7^{* *}$ \\
\hline
\end{tabular}

Note: $\quad\left(^{*}\right)$ - Statistically significant difference $(\mathrm{p}<0,05)$ compared to control group;

$\left({ }^{* *}\right)$ - Statistically significant difference $(\mathrm{p}<0,05)$ compared to previous time point

Table 1: Immunological indicators of white rats at different times of neurogenic stress $(M \pm S D, \%, g / l)$.

24 hours after immobilization, functional state of the cellular immunity changes were observed: migration speed assessed using leukocyte migration inhibition test (LMIT) increased by 75,6\% and suppressor cell index decreased by $14,6 \%$ compared to control group. There were also changes in the function of the humoral immunity: decrease in level of circulating immune complexes (CIC) and antibody-forming cells (AFC) by $48.5 \%$ and 2.0 times, respectively, compared with the control group. At the same time point, there were changes in nonspecific resistance of the organism, which were expressed in a significant decrease in $(2.9$ times compared to control group).

48 hours after immobilization, significant changes affected only the humoral immunity and nonspecific resistance of the organism. CIC and AFC levels decreased by $48.6 \%$ and $7.7 \%$, respectively. At the same time, phagocytic activity increased 2.1 times.

Later, 72 and 120 hours after immobilization, changes in the parameters of cellular and humoral immunity, as well as non-specific resistance of the organism, were of a multidirectional nature, reverting to original values.

The results of an experimental study of the immune system in neurogenic stress indicate that immobilization of animals has a modulating effect on the cellular link of immunity and a depressing effect on humoral immunity and nonspecific resistance of the organism.

Thus, the results of our study of the immune system function indices in adaptation processes allow us to conclude that various stressful effects cause changes in the functional state of the immune system and ultimately lead to immune dysfunction and secondary immunodeficiency states.

The study of the metabolism of purine nucleotides under neurogenic stress was carried out in the lymphocytes of August rats. Intact animals were in the control group. The study group included animals with neurogenic stress caused by immobilization. The results of the study are presented in Table 2 . 


\section{Virology \& Immunology Journal}

\begin{tabular}{|c|c|c|c|c|c|}
\hline \multirow{2}{*}{ Indices } & \multirow{2}{*}{ Control group } & \multicolumn{4}{|c|}{ Time after stress was caused } \\
\cline { 3 - 6 } & & $\mathbf{2 4}$ hours & $\mathbf{4 8}$ hours & $\mathbf{7 2}$ hours & $\mathbf{1 2 0}$ hours \\
\hline 5'-НТ & $1.18 \pm 0.34$ & $6.97 \pm 2.10^{*}$ & $7.53 \pm 2.25^{*}$ & $10.04 \pm 2.57^{*}$ & $10.06 \pm 0.27^{*}$ \\
\hline АДА & $1.51 \pm 0.28$ & $0.85 \pm 0.23^{*}$ & $0.94 \pm 0.29^{*}$ & $1.79 \pm 0.46^{* *}$ & $1.10 \pm 0.29^{* *}$ \\
\hline АМФ-ДА & $0.64 \pm 0.18$ & $1.57 \pm 0.43^{*}$ & $1.31 \pm 0.36^{*}$ & $1.88 \pm 0.37^{* *}$ & $1.94 \pm 0.64^{*}$ \\
\hline 5'-НТ/АМФ-ДА & $1.844 \pm 0.212$ & $4.439 \pm 0.857^{*}$ & $5.748 \pm 1.238^{*}$ & $5.340 \pm 1.046^{*}$ & $5.186 \pm 1.224^{*}$ \\
\hline АДА/АМФ-ДА & $2.359 \pm 0.383$ & $0.541 \pm 0.242^{*}$ & $0.718 \pm 0.248^{*}$ & $0.952 \pm 0.312^{*}$ & $0.567 \pm 0.152^{* *}$ \\
\hline
\end{tabular}

Note: $\quad(*)$ - Statistically significant difference $(p<0,05)$ compared to control group;

$\left({ }^{* *}\right)$ - Statistically significant difference $(\mathrm{p}<0,05)$ compared to previous time point

Table 2: Activity of purine metabolism enzymes in August rat lymphocytes in neurogenic stress $(M \pm S D, n m o l / m g \times s)$.

The activity of 5 '-nucleotidase in the lymphocytes of the animals studied 24 hours after the stress increased 5.9 times in comparison with the control group and tended to grow further. The activity of lymphocyte adenosine deaminase 24 hours after immobilization, on the contrary, decreased by $43.7 \%$ in comparison with the control. However, after 72 hours, activity of adenosine deaminase increased to match initial value. The activity of AMP-deaminase in the lymphocytes of the study group increased 2.4 times in comparison with the control 24 hours after the exposure and later maintained high values [12-20].

The ratios of activity of 5'-nucleotidase/AMPdeaminase (" $A$ " ratio) and adenosine deaminase/AMPdeaminase ("B" ratio) were assessed. Results indicate an increase in the A ratio 24 hours after the stress effect by 2.4 times in comparison with the control group. In later time points, the " $\mathrm{A}$ " ratio retained high values. " $\mathrm{B}$ " ratio, on the contrary, decreased 24 hours after immobilization 4.4 times in comparison with the control group and further maintained low values.

These data indicate that neurogenic stress causes changes in the metabolism of purine nucleotides, which is manifested by an increase in the activity of 5'nucleotidase and AMP-deaminase and a decrease in the activity of adenosine deaminase in lymphocytes. Changes in the activity of these enzymes might lead to impairment of the functions of immune cells. This assumption can be verified by matching immune system functional indices and the activity of purine nucleotides' metabolism enzymes in lymphocytes.

Thus, the results of the study of the metabolism of purine nucleotides in adaptation processes indicate that neurogenic stress causes an increase in the activity of 5'nucleotidase and AMP-deaminase and a decrease in the activity of adenosine deaminase in the lymphocytes of experimental animals.
Summarizing the results of the study of changes in the immune system and the metabolism of purine nucleotides, the following conclusions can be stated [2134].

Various stressful effects cause changes in the functional state of the immune system and ultimately lead to immune dysfunction and secondary immunodeficiency states. Thus, in experimental neurogenic stress, despite the modulating effect of immobilization on the cellular link of the immune system of experimental animals, inhibition of humoral immunity and nonspecific resistance of the organism occurs. At the same time, neurogenic stress causes an increase in the activity of 5'nucleotidase and AMP-deaminase and a decrease in the activity of adenosine deaminase in the lymphocytes of experimental animals.

\section{Summary}

The analysis of literature data and the results of the study of the functional state of the adreno-thyroid system under experimental neurogenic stress showed that the reduction of capture of catecholamines by the heart tissues is the basis of the revealed disorders. This, in turn, can lead to prolonged adrenergic impulses, and then to depletion of catecholamine content in tissues. At the same time, depletion of tissue catecholamine stores in case of neurogenic stress can be associated with a violation of the norepinephrine reuptake mechanism by the adrenergic neuron. In this case, the implementation of the sympathetic signal in the tissues of the myocardium is impaired before adenylate cyclase step, which leads to a disruption of the function of the myocardial adrenoreceptors during the mediator seizure step. The redistribution of thyroid hormones in the mitochondria of myocardial cells under neurogenic stress can be of an adaptive nature aimed at stimulating synthetic and bioenergetic processes in the myocardium in response to the amplification and then exhaustion of sympathetic 


\section{Virology \& Immunology Journal}

impulses. In this case, both thyroxine and norepinephrine increase the activity of myocardial adenylate cyclase directly, which might be associated with an increase in the sensitivity of the $\beta$-adrenergic receptors in the myocardium.

Thus, in neurogenic stress, prolonged adrenergic impulses might lead to depletion of tissue catecholamine stores via the decrease in the reuptake of catecholamines by tissues.

\section{References}

1. Abramov V, Abramova T, Egorov D, Vardosanidze KB (2001) Vichaia nervnaia deiatelnost i immunitet. Novosibirsk: SO RAMN pp: 123.

2. Baevskii R, Berseneva A (1997) Ocenka adaptacionnich vozmognostei organizma I risk razvitiia zabolevanii. pp: 234 .

3. Nikonov V (2002) Stress: Sovremenii patofiziologicheskii podchod $\mathrm{k}$ lecheniu. Chsrkov: Konsum pp: 240.

4. Sapin M, Nikituk D (2000) Immunnaia sistema, stress I immunodeficit. pp: 184.

5. Sudacov K (1981) Sistemnii mechanizmi emocionalnogo stressa. Medicina pp: 229.

6. Synnestvedt K, Furuta GT, Comerford KM, Louis N, Karhausen J, et al. (2002) Colgan Ecto-5'-nucleotidase (CD73) regulation by hypoxia-inducible factor-1 mediates permeability changes in intestinal epithelia. J Clin Invest 110(7): 993-1002.

7. Llupia J, Gras J, Llenas J (2003) Comparative antiallergic effects of second-generation H1antihistamines ebastine, cetirizine and loratadine in preclinic models. Arzneimittelforschung 53(2): 93-97.

8. Voziianov A, Butenko A, Zak K (1998) Citicini. Biologicheskii I protivoopucholevii svoistva. Kiev pp: 313.

9. Selle G (1982) Stress bez distressa. Progress pp: 126 .

10. Williams D (2003) Pregnancy: a stress test for life. Curr Opin Obstet Gynecol 15(6): 465-471.

11. Tapbergenov T (1998) Sposob ocenki funkcionalnoi polnocennosti immuniteta.
12. Evseeva M, Pshennikova M (2002) Sravnitelnaia ocenka razlichnich vidov adaptacionnoi zashiti miocarda pri stresse. Exper. Kardiologiia 4: 51-54.

13. Nikolenko U, Siniachenko O, Diadik A (1988) Immunodeficit, sviazanii $s$ nedostatkom fermentov purinovogo obmena. Immunologiia 1: 19-22.

14. Alonso R, Griebel G, Pavone G, Stemmelin J, Le Fur G, et al. (2004) Blockade of CRF1 or V1B receptors reverses stress-induced suppression of neurogenesis in a mouse model of depression. Mol Psychitry 9(3): 278-286.

15. Budihardjo I, Oliver $\mathrm{H}$, Lutter $\mathrm{M}$, Luo X, Wang X (1999) Biochemical pathways of caspase activation during apoptosis. Annu Rev Cell Dev Biol 15: 269-290.

16. Kadenbach B, Arnold S, Lee I, Huttemann M (2004) The possible role of cytochrome $c$ oxidase in stressinduced apoptosis and degenerative diseases. Biochim Biophys Acta 1655(1-3): 400-408.

17. Karbownik M, Zasada K, Wyczechowska D, Lewinski A, Fabianowska-Majewska K (2002) Purine metabolism in leukocytes and erythrocytes in Graves's and Hashimoto's disease. Endocr Res 28(3): 207-215.

18. Maloyan A, Horowitz M (1985) beta-Adrenergic signaling and thyroid hormones affect HSP72 expression during heat acclimation. J Appl Physiol 93(1): 107-115.

19. Mangiagalli A, Samuele A, Armentero MT, Bazzini E, Nappi G, et al. (2004) Effects of homocysteine on apoptosis-related proteins and anti-oxidant systems in isolated human lymphocytes. Eur J Biochem 271(9): 1671-1676.

20. Maragos WF, Young KL, Altman CS, Pocernich CB, Drake J, et al. (2004) Striatal damage and oxidative stress induced by the mitochondrial toxin malonate are reduced in clorgyline-treated rats and MAO-A deficient mice. Neurochem Res 29(4): 741-746.

21. Mass M, Simo E, Dragon S (2003) Erythroid pyrimidine 5'-nucleotidase: cloning, developmental, expression, and regulation by cAMP and in vivo hypoxia. Blood 102(12): 4198-4205.

22. Matsui $H$, Shimosawa $T$, Itakura $K$, Guanqun $X$, Ando K, et al. (2004) Adrenomedullin Can Protect Against 
Pulmonary Vascular Remodeling Induced by Hypoxia. Circulation 109: 2246-2251.

23. Middlekauff HR, Shah JB, Yu JL, Hui K (2004) Acupuncture effects on autonomic responses to cold pressor and handgrip exercise in healthy humans. Clin Auton Res 14(2): 113-118.

24. Pesi R, Micheli V, Jacomelli G, Peruzzi L, Camici M, et al. (2000) Cytosolic 5'-nucleotidase hyperactivity in erythrocytes of Lesch-Nyhan syndrome patients. Neuroreport 11(9): 1827-1831.

25. Rougier A, Auvergne R (2004) Adult brain neurogenesis and pathology. Neurochirurgie 50(1): 33-41.

26. Sanders JE, Goldstein BS, Leotta DF (1995) Skin response to mechanical stress: adaptation rather than breakdown-a review of the literature. J Rehabil Res Dev 32(3): 214-226.

27. Santos AM, Nobre EL, Garcia e Costa J, Nogueira PJ, Macedo A, et al. (2002) Grave's disease and stress. Acta Med Port 15(6): 423-427.

28. Tada K, Kasamo K, Suzuki T, Matsuzaki Y, Kojima T (2004) Endogenous 5-HT inhibits firing activity of hippocampal CA1 pyramidal neurons during conditioned fear stress-induced freezing behavior through stimulating 5-HT1A receptors. Hippocampus 14(2): 143-147.

\section{Virology \& Immunology Journal}

29. Tsigos C, Chrousos GP (2002) Hypothalamicpituitary-adrenal axis, neuroendocrine factors and stress. J Psychosom Res 53(4): 865-871.

30. True Al, Rahman A, Malik AB (2000) Activation of NF$\mathrm{kB}$ induced by $\mathrm{H} 202$ and TNF-a and its effects on ICAM-1 expression in endothelial cells. Am J Physiol Lung Cell Mol Physiol 279: L302-311.

31. Wetherell MA, Hyland ME, Harris JE (2004) Secretory immunoglobulin A reactivity to acute and cumulative acute multi-tasking stress: relationships between reactivity and perceived workload. Biol Psychol 66(3): 257-270.

32. Wykretowicz A, Furmaniuk J, Smielecki J, DeskurSmielecka E, Szczepanik A, et al. (2004) The oxygen stress index and levels of circulating interleukin-10 and interleukin-6 in patients with chronic heart failure. Int J Cardiol 94(2-3): 283-287.

33. Yegutkin G, Bodin P, Burnstock G (2000) Effect of shear stress on the release of soluble ectoenzymes ATPase and 5'-nucleotidase along with endogenous ATP from vascular endothelial cells. Br J Pharmacol 129(5): 921-926.

34. Zimmermann U, Spring K, Kunz-Ebrecht SR, Uhr M, Wittchen HU, et al. (2004) Effect of Ethanol on Hypothalamic-Pituitary-Adrenal System Response to Psychosocial Stress in Sons of Alcohol-Dependent Fathers. Neuropsychopharmacology 29(6): 11561165.

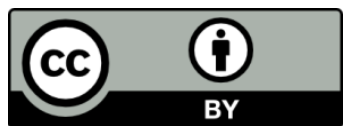

